\title{
Sociobiology
}

RESEARCH ARTICLE - ANTS

\section{Induced Biotic Response in Amazonian Ant-Plants: the Role of Leaf Damage Intensity and Plant-Derived Food Rewards on Ant Recruitment}

\author{
T GONÇALVES-SOUZA
}

Universidade Federal Rural de Pernambuco (UFRPE), Recife-PE, Brazil

\section{Article History}

\section{Edited by}

Gilberto M. M. Santos, UEFS, Brazil

Received 25 April 2016

Initial acceptance 24 August 2016

Final acceptance 18 September 2016

Publication date 25 October 2016

\section{Keywords}

Myrmecophytes, herbivory, protective mutualism, Ant-plant interaction.

\section{Corresponding author}

Thiago Gonçalves-Souza

Laboratório de Ecologia Filogenética e

Funcional, Departamento de Biologia

Área de Ecologia

Universidade Federal Rural de

Pernambuco (UFRPE)

Rua Dom Manoel de Medeiros, s/no

CEP 52171-900, Recife-PE, Brasil

E-Mail: tgoncalves.souza@gmail.com

\begin{abstract}
Although plant-ants respond to cues indicating the presence of herbivores, it remains unclear how ant workers are stimulated by herbivory cues with varying intensity. I hypothesized that ants respond more quickly to severe foliar damage and that ants inhabiting myrmecophytes that provide food resource recruit workers to any intensity of foliar damage. I tested the induced response in three ant-plant systems: two that provide food resources and another one that does not provide. I simulated leaf damage using different concentrations of foliar extracts. In all systems, the plant-ant recruitment increased after damage simulations. In food providing systems, ants did not distinguish between different intensity damages, although one system has shown a mixed response to that intensity. This result indicates that ants defend more intensely their host plant to avoid injuries that diminish food provisioning. In the non-food providing system ants responded more quickly to the simulation of high foliar damage. This faster recruitment to leaves with high damage suggests that ants are searching for hot spots that potentially have more insects for feeding on. I suggested that future works could manipulate plant size and quality, and food provisioning to better understand why mutual ant-plant systems with very distinct characteristics are evolutionarily stabilized.
\end{abstract}

\section{Introduction}

Mutualistic interactions are characterized by a network of mutual benefits in which two species increase their fitness (survival, reproduction) when occurring together (Bronstein, 1998). Mutualistic interactions between plant and animals occur when plants provide resources to animal partners, and animals, in turn, provide services (e.g., transport, protection) (Del-Claro et al., 2016). A widespread mutualistic interaction in nature is the association of myrmecophyte plants and ants (Fonseca \& Ganade, 1996). Whereas myrmecophytes benefit ants offering shelter (domatia) and/or food resources (food bodies), ants defend myrmecophytes from natural enemies and could decrease herbivory (Bronstein, 1998; Bronstein et al., 2006). Host plant defense is mediated by the recruitment of ant workers to plant regions with herbivore or herbivore cues, such as leaf volatile compounds released after the damage (Agrawal, 1998; Agrawal \& Rutter, 1998; Brunaet al., 2004). Ant protection increases host plant leaf area, survival rates, and seed set (Heil \& McKey, 2003). The inducible defense, driven by plant tissue volatiles, is known as induced biotic response. In general, plants allocate resource to ants when the provisioning of this resource increases their fitness (Karban \& Myers, 1989). Theoretically, these complex changes in plant inducible response enhance the resistance of plants to further attack of herbivores (reviewed by Karban \& Myers, 1989). Experimental studies have been showing that herbivory simulations (e.g., leaf damage or chemical stimuli with leaf extracts) stimulate ant recruitment to those damaged regions (Agrawal, 1998; Romero \& Izzo, 2004). However, those studies have focused on how ants respond to different stimuli (visual, chemical), but few studies compared ant-plant 
systems that have different features, such as food rewards and ant partners.

The intensity (velocity and number of workers recruited) of the response of ant partners to the damaged regions dependent on several factors. For instance, it has been suggested that plant age and structure and the provisioning of food resources are essential elements, determining the response of ant partners to herbivore cues and, thus, their efficiency in host plant protection (Heil \& Mckey, 2003; Izzo \& Vasconcelos, 2005; Trager \& Bruna, 2006). For instance, Calixto et al. (2015) showed that anti-herbivore defenses of Qualea multiflora (Vochysiaceae) vary along plant development, from higher sugar concentration in young leaves attracting more ants (a biotic protection), to higher foliar toughness (an abiotic defense), which both contribute to decreasing herbivore attacks (see also Del-Claro et al., 2016). Previous studies showed that plant size is positively related to colony size which, in turn, affects the number of available ant workers for patrolling plant leaves (Christianini \& Machado, 2004). Consequently, plant species with varying sizes and leaves with different ages could have different responses to herbivore attacks because they have more (or less) ant workers (Christianini \& Machado, 2004; Calixto et al. 2015). Accordingly, different cues could favor (or disfavor) the attraction of ants and the consequent defense of plants against their natural enemies (Heil \& McKey, 2003; RicoGray \& Oliveira, 2007). Whereas some myrmecophytes offer both food resources and shelter (e.g., Maieta), other species offer only shelter (e.g., Hirtella) (Vasconcelos \& Davidson, 2000; Izzo \& Vasconcelos, 2002; Christianini \& Machado, 2004). The variety of ant-plant systems with and without food rewards can potentially attract ant partners that respond differentially to herbivore cues, from protective partners to commensals. Moreover, even within the same plant species, the quality and amount of resources offered affect ant species (reviewed in Heil \& Mckey, 2003).

Ants associated with myrmecophytes that do not provide food depend on arthropods (mainly herbivores) that forage on their host plants. Thus, it is expected that only reliable cues of herbivory (high concentration of chemical volatiles) could elicit ant recruitment in an ant-plant system without food rewards. Conversely, plant-ants associated with myrmecophytes that offer both food and shelter have the advantage of feeding directly on plants and, thus, should respond to any herbivory cues because they are interested in the vigor, growth and survival of their host plant, especially in those obligate inhabitants (Heil \& McKey, 2003).

I compared the response of ants to herbivory cues (different concentrations of leaf extracts) in three ant-plant systems in Central Amazonia with and without provisioning of food rewards. I hypothesized that ant workers recruitment depends (i) on the intensity of leaf damage (low vs. high cues of herbivory) and (ii) that ant recruitment varies with the provisioning of food rewards. I predicted that the recruitment of ant workers associated with myrmecophytes that do not provide food reward (e.g., Hirtella) is triggered only by strong herbivory cues, such as in treatments with a high concentration of leaf extract. On the other hand, in ant-plants that provide food (e.g., Maieta) the ant recruitment occurs at any intensity (from low to high concentrations of leaf extract) of herbivory cues.

\section{Material and Methods}

\section{Study site and organisms}

The experiments were performed on August 2007 in a terra-firme Amazonian rainforest (Reserve 1501: $2^{\circ} 24^{\prime} \mathrm{S}$, $59^{\circ} 43^{\prime}$ 'W) administrated by Biological Dynamics of Forest Fragment Project of the National Institute for Amazonian Research (INPA). This forest is located $80 \mathrm{Km}$ north of Manaus city, Amazonia, Brazil. The climate is classified as $\mathrm{Am}$ in the Köppen system with average rainfall from 1900 to $2500 \mathrm{~mm} /$ year, with a dry season between June and October and rainy season from November to May (Lovejoy $\&$ Bierregaard, 1990). I used three myrmecophytes, Maieta guianensis and Tococa bullifera (Melastomataceae), and Hirtella myrmecophila (Chrysobalanaceae) commonly found in the understory of terra-firme forest.

M. guianensisis a shrub with height varying from 0.5 to 1.5 meters that has the plant-ant Pheidole minutula as the main mutualistic partner; their leaves have two-three domatia and plants produce food bodies used by $P$. minutula ants (Vasconcelos, 1991). Specimens of P. minutula are obligate plant-ants and the dominant species occurring on $M$. guianensis (Vasconcelos,1991,1993). T. bullifera is a shrub with height varying from 0.5 to 1.5 meters. This ant-plant produces Mullerian bodies that are used mainly by Azteca spp. (Vasconcelos \& Davidson, 2000).Their domatia are heartshaped and inserted in the leaf base, where queens of Azteca spp. establish a colony (Vasconcelos \& Davidson, 2000) (Fig 1a). I did not quantify the nutritional content of food bodies produced by these two myrmecophytes, but other studies have indicated the presence of glycogen, lipids, and carbohydrates (reviewed in Rico-Gray \& Oliveira, 2007; see also Vasconcelos, 1991). H. myrmecophila (Chrysobalanaceae) is a shrub with height varying from 0.5 to 8 meters that houses the plant-ant Allomerus octoarticulatus (Fonseca, 1999). Ant workers of $A$. octoarticulatus feed exclusively on insects that forage over H. myrmecophila leaves because these plants do not offer any food reward for ants. Their leaves have a pair of domatia inserted in the base (Romero \& Izzo, 2004). All organisms will be hereafter mentioned by their genus.

\section{Effects of damage intensity on ant recruitment}

To test how damage intensity affects the velocity of ant workers recruitment I selected 30 plants of each species 
A) Ant-plant systems: does host plant provide food reward for ants?

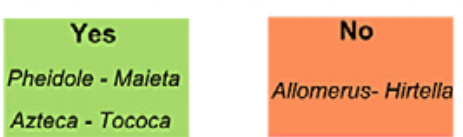

B) Response velocity: Time for doubling the number of ants recruited

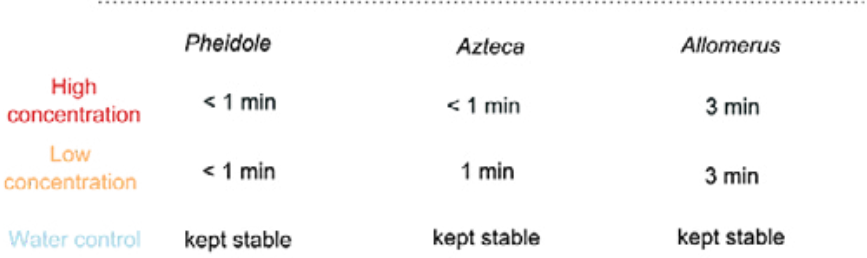

C) Pheidole - Maieta

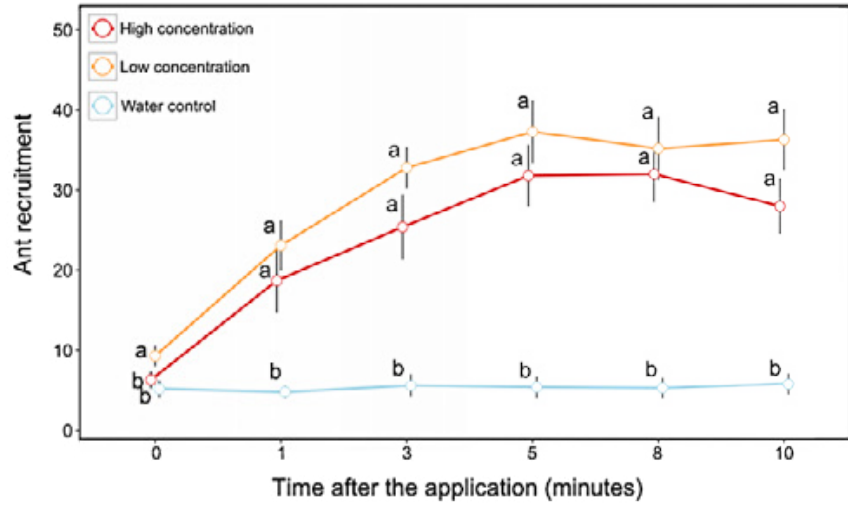

D) Azteca - Tococa

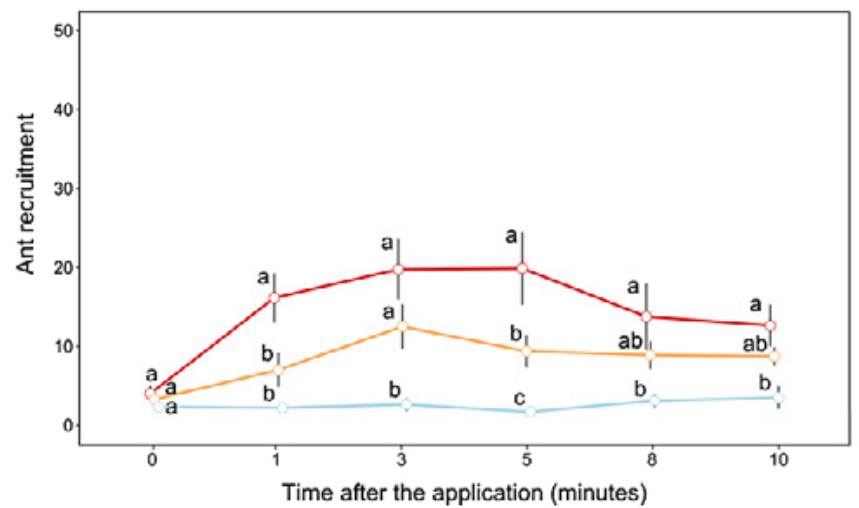

E) Allomerus - Hirtella

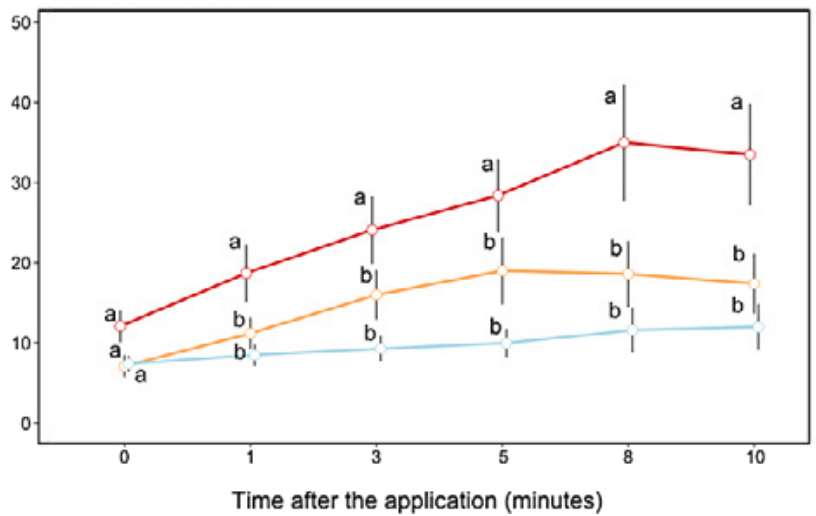

Fig 1. Basic description of studied ant-plant systems concerning (a) the provisioning of food rewards and (b) the time the number of ants recruited after the application of foliar extracts is doubled. Ant recruitment (average number of ants \pm 1SE) to young leaves of (c) Maieta guianensis, (d) Tococa bullifera, and (e) Hirtella myrmecophila after the application of foliar extracts with high (red colour) and low concentration (orange colour) and water control (blue colour). Different letters comparing the average values mean significant difference $(P<$ 0.05: Tukey HSD). Detailed information about treatment and time effects can be found in Table 1 .

varying from 0.5 to 2.5 meters in the understory of the terrafirme forest. I randomly picked one young leaf on the top of each plant to perform the experiment. I divided those 30 plants into three different treatments: 1) high damage concentration $(\mathrm{n}=10$ plants), in which the leaf received three drops of an extract with concentration of $20 \mathrm{~g}$ of leaf tissue macerated per $80 \mathrm{ml}$ of water $(0.25 \mathrm{~g} / \mathrm{ml}) ; 2)$ low damage concentration $(\mathrm{n}=10)$, in which the leaf received three drops of an extract with concentration of $1 \mathrm{~g}$ of young leaves per $80 \mathrm{ml}$ of water $(0.0125 \mathrm{~g} / \mathrm{ml}) ; 3)$ water control $(\mathrm{n}=10)$, in which each leaf received three drops of water. Those drops were applied with syringes. I counted the number of ant workers immediately before the application (hereafter mentioned as moment 0 ), and 1, 3, 5, 8 and 10 minutes after the application of foliar extracts or water. I performed this procedure on all three systems, Pheidole-Maieta, Azteca-Tococa and AllomerusHirtella and selected plants occurring at the same site. The amount of leaf tissue per water that I categorized "high" and "low" concentration was defined after previous attempts that manipulate the same ant plant systems; Lapola et al. (2003) with Pheidole-Maieta, Bruna et al. (2004) with AztecaTococa, and Romero and Izzo (2004) with Allomerus-Hirtella. These authors compared water vs. foliar extract (without comparison of intensity) and arbitrarily defined an amount of leaf tissue per water (or methanol). For example, whereas Romero and Izzo (2004) used $5 \mathrm{~g}$ of fresh leaves per $80 \mathrm{ml}$ of water, Bruna et al. (2004) used $5 \mathrm{~g}$ of fresh leaves per $60 \mathrm{ml}$ of methanol. Thus, the treatments were categorized by arbitrarily multiplying the amount of $5 \mathrm{~g}$ of leaf tissue by four to define high concentration and dividing this amount by five to define low concentration. Importantly, the studies I used to define my treatments found a strong effect of leaf extract on ant recruitment. In fact, the use of leaf tissue extracts is common in studies with myrmecophytes, and they are considered a chemical stimulus, indicating possible attacks of herbivores (Lapola et al., 2003; Romero \& Izzo, 2004).

\section{Statistical analyses}

I used repeated measures analysis of variance (ANOVA) to test if the concentration of leaf extracts affects the number of ant workers over time. I considered treatments as a fixed effect and time as the factor of repetition. To avoid sphericity, I corrected probabilities with the Greenhouse-Geisser (GG) method (Quinn \& Keough, 2002). I used Tukey HSD $a$ posteriori test for comparing the number of ants between 
treatments at each time (Quinn \& Keough, 2002). I utilized the software Statistica13.0 to run these analyses.

\section{Results}

I found on average $19.03( \pm 10.4 \mathrm{SD})$ Pheidole ants per domatia of Maieta, 50.4 ( \pm 36.6 SD) Allomerus ants per domatia of Hirtella, and 60.6 ( \pm 29.6 SD) Azteca ants per domatia of Tococa.

The number of ant workers was higher on leaves with foliar extract (high and low concentration) than on leaves with water drops in all studied species. There was a significant effect of both treatment and time (Table 1). Whereas the number of Pheidole ants increased 5.1 times after 1 minute of the chemical stimuliin Maieta leaves (Fig 1b, c), the number of Allomerus and Azteca increased 2.89 and 4.96 times in Hirtella and Tococa leaves, respectively (Figs 1b, d, e).

The number of Pheidole ants did not differ between leaves with high and low stimuli $(P>0.05$ for all time comparisons, Tukey HSD), although they both differed from water control $(P<0.001$; Fig 1c). However, the number of Azteca ants has a mixed response to the chemical stimuli through time. Even though ant recruitment was higher in treatments compared with water control, ant numbers were similar between low and high stimuli only after 3 minutes of the application (Fig 1d). Conversely, the number of Allomerus ants was greater in high concentration stimuli than on low concentration $(P<0.05$ for all time comparisons, Tukey HSD) and water control $(P<0.05$ for all time comparisons, Tukey HSD) after of the application of leaf extract (Fig 1e).

\section{Discussion}

In this study, I examined whether the intensity of leaf damage and the provisioning of food rewards affect ant workers recruitment. As predicted, ant workers associated with food providing systems did not distinguish between damage intensity, confirming the hypothesis that the provisioning of resource increases plant defense by ants. Also, I confirmed the prediction that ant workers associated with plants that do not provide foods respond only to strong herbivory cues.

Previous studies have indicated that the intensity of ant response to herbivory varies depending on ant species and the host plant they are associated with (Heil \& McKey, 2003; Bruna et al. 2004; Heil 2015; Del-Claro et al., 2016). Specifically, the provision of food rewards by myrmecophytes could elicit best ant partners (i.e., a more efficient defense against herbivores) when compared with plants that do not provide those rewards (Risch \& Rickson, 1981; Heilet al., 1997; Izzo \& Vasconcelos, 2002). In fact, previous studies demonstrated that the provisioning of food increase ant aggressiveness (against plant herbivores) and survival rates (reviewed in Heil, 2015).

The results showed that the number of ant workers of Pheidole, Azteca, and Allomerus increases rapidly after the application of leaf extracts, which are cues indicating herbivore attacks. As expected, the number of Allomerus ants was three times higher in leaves with high chemical stimuli compared with low stimuli. Indeed, only strong and reliable cues indicating the presence of herbivores stimulated the recruitment of ants that need to catch these insects for feeding.

Table 1. Repeated measures ANOVA showing the effects of treatments (high and low concentration extracts, and water control) and time (0, $1,3,5,8$, and 10 minutes after the application of the treatments) on ant recruitment.

\begin{tabular}{|c|c|c|c|c|}
\hline Myrmecophytes / plant-ants & Effect & DF & $F$ & $\boldsymbol{P}$ \\
\hline \multirow{3}{*}{ Maieta guianensis / Pheidole minutula } & Treatment & 2 & 35.25 & $<0.001$ \\
\hline & Time & 5 & 75.26 & $<0.001$ \\
\hline & Time vs. Treatment & 10 & 17.98 & $<0.001$ \\
\hline \multirow{4}{*}{ Hirtella myrmecophila / Allomerus octoarticulatus } & Treatment & 2 & 6.339 & 0.006 \\
\hline & Error & 27 & & \\
\hline & Time & 5 & 27.84 & $<0.001$ \\
\hline & Time vs. Treatment & 10 & 3.45 & $<0.001$ \\
\hline \multirow{4}{*}{ Tococa bullifera / Azteca sp. } & Error & 23 & & \\
\hline & Time & 5 & 12.41 & $<0.001$ \\
\hline & Time vs. Treatment & 10 & 4.86 & $<0.001$ \\
\hline & Error & 115 & & \\
\hline
\end{tabular}


Besides, it is possible that Allomerus workers respond only to strong chemical stimuli because Hirtella plants are big and they architecture is too complex (Izzo \& Vasconcelos, 2005). Therefore, low chemical stimuli concentration may be not strong enough to trigger a fast and localized response of ants to leaves with low damage because they are not detected by ants and/or because the higher plant size does not favor stimuli transmission. In fact, the number of ant workers in leaves with low concentration extract did not differ from leaves with water.

The results I found reinforce previous studies showing that ants respond to leaf volatile compounds by increasing recruitment to damaged areas (Agrawal, 1998; Agrawal \& Rutter, 1998; Bruna et al., 2004; Christianini \& Machado, 2004; Romero \& Izzo, 2004). Notwithstanding, I did not found any difference between the concentration of foliar extracts in Pheidole-Maieta system; actually, Pheidole ants responded to the minimum cue of herbivory. I suggest that the small size of Maieta facilitates the transmission of chemical cues throughout the plant favoring ant recruitment. Accordingly, by increasing the intensity of ant recruitment those workers could decrease leaf herbivory and benefit their mutualistic host plant. Indeed, Agrawal and Rutter (1998) demonstrated that foliar damage decline plant vigor which, in turn, reduces resource quality to ants. Therefore, in ant-plants with limited food supply and with a small number of leaves, the intensity of ant recruitment is essential to guarantee food provisioning (Itino et al., 2001) and to stabilize these mutualistic systems. However, contrary to my expectations, there was a mixed, time-dependent response of Azteca ants to chemical volatiles intensity. On one hand, these ants did not differentiate low concentration from water control after 1, 5, 8, and 10 minutes after the stimuli, which disagree with the expected response. On the other hand, ants responded similarly between high and low concentrations after 3 minutes, which was expected based on the rewards provided by Tococa plants. These mixed results reinforce the importance of food rewards to ant recruitment, but also shows there are other factors dictating plant defense by ants (see, e.g., Calixto et al. 2015). For example, ant patrolling can be associated with the number of leaves with domatia (Christianini \& Machado, 2004) and, therefore, a fast response to chemical stimuli may depend on the real number of domatia present in the host plant (see also Del-Claro et al., 2016 for other important cues eliciting host plant defense by ants).

The results showed that chemical cues associated with herbivory increase ant recruitment to potentially damaged leaves in three Amazonian ant-plant systems. More importantly, these findings demonstrated that in ant-plant systems based on food rewards (such as Maieta) ant workers defend their host plants in any chemical clue indicating the presence of potential herbivores, although the response of Tococa ants was mixed. Conversely, ant partners foraging on one plant species that do not provide food resource respond mainly to chemical cues indicating intense foliar damage. These results suggest the provisioning of food in ant-plant systems drive the intensity of ant recruitment to damaged areas. However, it is important to recognize that these finding should be tested in other systems (mainly from plants that do not provide rewards). For example, plant size could affect the way ant workers respond to that chemical stimulus (Christianini \& Machado, 2004). Future works could manipulate plant architecture (size, number of branches), quality (number of active domatia) and food provisioning to understand better why mutual ant-plant systems with very distinct characteristics are evolutionarily stabilized.

\section{Acknowledgments}

I would like to thank the students of the Ecology Discussion Group (FFun-Club) that kindly revised early versions of this manuscript: T.N. Bernabé, P.H.P. Gusmão, L.S.O. Melo, and P.H.A. Sena. T. Izzo, G. Machado and G. Q. Romero helped with fundamental ideas before the experiment. The Biological Dynamics of Forest Fragments Project (INPA/Smithsonian) has partially supported this study. This is the publication 703 in the technical series of the Biological Dynamics of Forest Fragments project.

\section{References}

Agrawal, A.A. (1998). Leaf damage and associated cues induce aggressive ant recruitment in a Neotropical ant-plant. Ecology, 79: 2100-2112.

Agrawal, A.A. \& Rutter, M.T. (1998). Dynamic anti-herbivore defense in ant-plants: the role of induced responses. Oikos, 83: 227-236.

Bronstein, J.L.(1998).The contribution of ant-plant protection studies to our understanding of mutualism. Biotropica, 30 : 150-161.

Bronstein, J.L., Alarcón, R. \& Geber, M. (2006). The evolution of plant-insect mutualism. New Phytologist, 172: 412-428. doi: $10.1111 /$ j.1469-8137.2006.01864.x

Bruna, E.M., Lapola, D.M. \& Vasconcelos, H.L. (2004). Interespecific variation in the defensive responses of obligate plant-ants: experimental tests and consequences for herbivory. Oecologia, 138: 558-565. doi: 10.1007/s00442-003-1455-5

Calixto, E.S., Lange, D.\& Del-Claro, K. (2015). Foliar antiherbivore defenses in Qualea multiflora Mart. (Vochysiaceae): changing strategy according to leaf development. Flora, 212: 19-23. doi: 10.1016/j.flora.2015.02.001

Christianini, A.V. \& Machado, G. (2004). Induced biotic responses to herbivory and associated cues in the Amazonian ant-plant Maieta poeppigii. Entomologia Experimentalis et Applicata, 112: 81-88. doi: 10.1111/j.00138703.2004.00188.x 
Del-Claro, K.,Rico-Gray, V., Torezan-Silingardi, H. M., Alves-Silva, E., Fagundes, R., Lange, D., Dáttilo, W., Vilela, A. A., Aguirre, A. \& Rodriguez-Morales, D. (2016). Loss and gains in ant-plant interactions mediated by extrafloral nectar: fidelity, cheats and lies. Insectes Sociaux, 63: 207-221. doi: 10.1007/s00040-016-0466-2

Fonseca, C.R. \& Ganade, G. (1996). Asymmetries, compartments and null interactions in an Amazonian ant-plant community. Journal of Animal Ecology, 65: 339-347.

Fonseca, C.R. (1999). Amazonian ant-plant interactions and the nesting space limitation hypothesis. Journal of Tropical Ecology, 15: 807-825.

Heil, M. (2015). Extrafloral nectar at the plant-insect interface: a spotlight on chemical ecology, phenotypic plasticity, and food webs. Annual Review of Ecology, Evolution and Systematics, 60: 213-232. doi: 10.1146/annurev-ento-010814-020753

Heil, M. \&Mckey, D. (2003). Protective ant-plant interactions as model systems in ecological and evolutionary research. Annual Review of Ecology, Evolution and Systematics, 34: 425-453. doi: 10.1146/annurev.ecolsys.34.011802.132410

Heil, M., Fiala, B., Linsenmair, K.E., Zotz, G. \& Menke, P. (1997). Food body production in Macaranga triloba (Euphorbiaceae): a plant investment in anti-herbivore defense via symbiotic ant partners. Journal of Ecology, 85: 847-861.

Itino, T., Otioka, T., Hatada, A. \& Hamid, A.A. (2001). Effects of food rewards offered by ant-plant Macaranga on the colony size of ants. Ecological Research, 16: 775-786. doi: 10.1046/j.1440-1703.2001.00433.x

Izzo, T.J. \& Vasconcelos, H.L.(2002). Cheating the cheater: domatia loss minimizes the effects of ant castration in an Amazonian ant-plant. Oecologia, 133: 200-205. doi: 10.1007/ s00442-002-1027-0

Izzo, T.J.\&Vasconcelos, H.L.(2005). Ants and plantsize shape the structure of the arthropod community of Hirtella myrmecophila, an Amazonian ant-plant. Ecological Entomology, 30: 650-656. doi: 10.1111/j.0307-6946.2005.00736.x

Karban, R. \& Myers, J.H. (1989). Induced plant responses to herbivory. Annual Review of Ecology, Evolution and
Systematics, 20: 331-348. doi: 10.1146/annurev.es.20.110 189.001555

Lapola, D.M., Bruna, E.M. \& Vasconcelos, H.L. (2003). to introduction of cues by ants inhabiting Maieta guianensis (Melastomataceae). Biotropica, 35: 295-230. doi: 10.1111/ j.1744-7429.2003.tb00288.x

Lovejoy, T.E. \& Bierregaard, R.O. (1990). Central Amazonian forests and the minimum critical size of ecosystem project. In Gentry AH (ed.), Four Neotropical Rainforests (pp 60-70). Yale University Press, New York.

Quinn, G.P. \& Keough, M.J. (2002). Experimental design and data analysis for biologists. Cambridge University Press, Cambridge.

Rico-Gray, V. \& Oliveira, P.S. (2007). The ecology and evolution on ant-plant interactions. The University of Chicago Press. Chicago.

Risch, S.J. \& Rickson, F.R. (1981). Mutualism in which ants must be present before plants produce food bodies. Nature, 291: 149-150.

Romero, G.Q. \& Izzo, T.J. (2004). Leaf damage induces ant recruitment in the Amazonian ant-plant Hirtella myrmecophila. Journal of Tropical Ecology, 20: 675-682. doi: 10.1017/S02 66467404001749

Trager, M.T. \& Bruna, E.M. (2006). Effects of plant age, experimental nutrition and ant occupancy on herbivory in a neotropical myrmecophyte. Journal of Ecology, 94: 11561163. doi: 10.1111/j.1365-2745.2006.01165.x

Vasconcelos, H.L. (1991). Mutualism between Maieta guianensis Aubl., a myrmecophytic melastome, and one of its ant inhabitants: ant protection against herbivores. Oecologia, 87: 295-298.

Vasconcelos, H.L. (1993). Ant colonization of Maieta guianensis seedlings, an Amazon ant-plant. Oecologia, 95: 439-443.

Vasconcelos, H.L. \& Davidson, D.W. (2000). Relationship between plant size and ant associates in two Amazonian antplants. Biotropica, 32: 100-111. doi: 10.1111/j.1744-7429. 2000.tb00452.x 